\begin{tabular}{|c|c|c|}
\hline (S) & $\begin{array}{c}\text { Türkiye Tarımsal Araştırmalar Dergisi } \\
\text { dergipark.gov.tr/tutad }\end{array}$ & $\begin{array}{l}\text { Turk J Agric Res } \\
\text { 2018, 5(3): 293-298 } \\
\text { ○ TÜTAD } \\
\text { ISSN: 2148-2306 }\end{array}$ \\
\hline 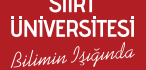 & Derleme / Review & $\begin{array}{l}\text { ISSN: } 2148-2306 \\
\text { e-ISSN: } 2528-858 X \\
\text { doi: } 10.19159 / \text { tutad.364655 }\end{array}$ \\
\hline
\end{tabular}

\title{
Bahçe Ürünlerinde Markalaşmanın Önündeki Engeller
}

\author{
Muharrem ÖZCAN* \\ Ondokuz Mayıs Üniversitesi, Ziraat Fakültesi, Bahçe Bitkileri Bölümü, Samsun, TÜRKIYYE
}

\begin{tabular}{l}
\hline Geliş Tarihi/Received: $11.12 .2017 \quad$ Kabul Tarihi/Accepted: 06.08.2018 \\
\hline ORCID ID \\
\hline (D) orcid.org/0000-0002-3237-7043 \\
*Sorumlu Yazar/Corresponding Author: muozcan@omu.edu.tr
\end{tabular}

Öz: Türkiye, ekolojik ve biyolojik zenginlikleriyle birlikte dünyada yüksek tarım potansiyeli yönüyle dikkat çeken bir ülkedir. Ülke toprağının yaklaşık \% 5'ini bahçe bitkileri tarımına ayıran Türkiye, bu özelliğiyle bahçe bitkileri ülkesi olarak adlandırılmaktadır. Anavatanı olduğu ürünler kadar anavatanı olmadığı subtropik hatta tropik kökenli ürünleri de kaliteli bir şekilde yetiştirebilen Türkiye'nin, yıllık bahçe bitkileri üretimi yaklaşık 48 milyon ton dolayındadır. Türkiye bahçe bitkileri tarımında, yeterli üretim ve kalite olmasına rağmen üretilen ürünlerde markalaşmanın çok düşük düzeyde kaldığı görülmektedir. Bunun en önemli nedenleri olarak birbirinden bağımsız hareket eden (arazi varlığı az) küçük işletme sayısının fazla olması, sofralık tüketimlerde marka aranmaması ve özellikle iç piyasaya sunulan ürünler için standardizasyonun yapılmaması gösterilebilir. Üreticilerin ekonomik gelir elde edebilmeleri, tüketicilerin kaliteli ürün tüketebilmeleri, ürün ve kalite kayıplarının azaltılabilmesi için kaliteli üretimler yanında marka olmaya ve markalaşmaya da önem verilmesi gerekmektedir.

Anahtar Kelimeler: Üretim, pazarlama, ekolojik zenginlik, biyolojik zenginlik

\section{Barriers to Branding in Horticultural Crops}

\begin{abstract}
Turkey is a country which attracts the world's attention with its ecological and biological wealth, and also with its high agricultural potential. Approximately, $5 \%$ of Turkey's lands were spared for horticulture. So, it is called as a country of horticulture. Turkey, which can grow subtropical and even tropical crops as well as the crops which's homeland is Turkey, can grow approximately 48 million $t$ of horticultural crops per year. It can be seen that branding in horticultural crops in Turkey is too low compared to its production quality and number. The main reasons for this problem are, there are so many establishments (with small land size) which act independently from each other, customers don't seek brands in table consumption and also, standardization rules don't apply to products which are for domestic market. In order to producers earn more income, consumers to consume products with quality and to reduce product and quality losses, importance should be also given to branding as well as quality production.
\end{abstract}

Keywords: Production, marketing, ecological wealth, biological wealth

\section{Giriș}

Türkiye'de biyolojik çeşitliliğin artmasında; sahip olduğu topoğrafik, coğrafik ve ekolojik çeşitlilik/zenginlik önemli rol oynamıştır. Türkiye'nin izdüşüm yüzölçümü $783562 \quad \mathrm{~km}^{2}$ olmasına karşın, gerçek yüzölçümü 814578 $\mathrm{km}^{2}$ ' dir. Aradaki $31016 \mathrm{~km}^{2}$ 'lik fark arazinin dağlık ve engebeli olmasından kaynaklanmaktadır (Anonim, 2018a). Arazi yapısındaki çeşitlilik farklı iklim özelliklerinin ortaya çıkmasına neden olmuştur. İklim çeşitliliği, Türkiye'de anavatanı olunan türlerin yanında, sonradan Türkiye'ye getirilen türlerin de rahatlıkla yetiştirilebilmesine uygun iklimlerin bulunabilmesini sağlamıştır. Buna güzel bir örnek olarak, çay ve muz gibi tropik 
kökenli türlerin Türkiye'de kaliteli bir şekilde yetiştirilebilmesi verilebilir.

Ekolojik zenginlikler tarımsal faaliyetler için firsatlar sunmaktadır. Ancak iyi bir üretim planlaması yapılmadığında yetiştiricilik, zorlama ve çok fazla ek girdi kullanılmasını zorunlu kılmaktadır. Bu durum, maliyetlerin yükselmesi yanında kalitede dalgalanmalara da neden olmaktadir.

İşlenmiş ürünlerde kalite, çeşitli gıda katkılarıyla standart hale getirilebilmesine karşın; sofralık ürünlerde kalite ürünün bahçeden geldiği duruma bağlı olarak tüketiciye ulaşmaktadır.

Gelişmiş ülkelerde, üretimden pazarlamaya kadar örgütlü bir yapıda hareket eden üreticiler, gerek kendileri ve gerekse ülkeleri için yararlar sağlamışlardır. $\mathrm{Bu}$ ülkelerdeki güçlü üretici örgütleri, tarım - sanayi ve pazarlama arasında olması gereken bağı başarıyla kurmuşlardır. Kurdukları pazarlama yapısıyla, pazardan daha fazla pay almışlar ve ürettikleri ürünlerden daha fazla gelir elde etme imkânına kavuşmuşlardır. Günümüzde, tarımsal örgütlenmenin en yaygın olduğu ve tarımsal örgütlenmenin geliştiği ülkelerin başında, Avrupa Birliği ülkeleri gelmektedir. Avrupa Birliği'nde, tarım kesimine yönelik politikaların oluşturulmasında ve bu politikaların uygulanmasında tarımsal örgütlerin önemli bir yeri olup, tarıma dayalı sanayiinin yaklaşık \% 50'si de bu örgütler aracılığıyla yürütülmektedir (Kızılaslan ve Doğan, 2013).

Türkiye' de bu anlamda yeterince örgütlenme olmamakla birlikte, mevcut örgütlerin üretim ve pazarlamada enregrasyonu yapmada etkili ve yetkili olmamaları, arz/talep dengesinin kurulmasındaki sorunların devam etmesine yol açmaktadır. Türkiye' de bahçe bitkileri alanında (Meyve grubunda 141, sebze-süs bitkileri grubunda 64 ve organik tarım alanında 21) toplam 226 birlik bulunmakta ve bunlara kayıtlı toplam üretici sayısı ise 19795 'dir (Anonim, 2018b). Bu rakam, bir bahçe bitkileri ülkesi olarak adlandırılan Türkiye'de örgütlenmedeki yetersizliği ortaya koymaktadır.

Türkiye'de üretici birliklerine, yasayla üretimi talebe göre planlamak, ürün kalitesini iyileştirmek gibi önemli görevler verilmiş olmasına karşın, birliklerin mevcut durumları bunları yapmalarının önünde bir engel oluşturmaktadır. Çünkü bu kuruluşlar, üreticilerin ürün veya ürün grubu bazında gönüllülük esasına göre oluşturdukları tüzel kişilikler şeklinde ortaya çıkan birlikteliklerdir. Üretici birliklerinin var olan yetkisini kullanmaması, üretim ve pazarlamanın birbirinden ayrı düşünülerek yapılan tarımsal faaliyetlerin devam etmesine neden olmaktadır. $\mathrm{Bu}$ durum markalaşmanın önünde bir engel oluşturmaktadır.

Bahçe ürünleri taze tüketimler için hasat sonrası ömürleri kısa olan ürünlerdir. Bunların üretimdeki kalitesiyle birlikte tüketime sunulabilmesi için arz/talep dengesinin kurulması yanında, öncelikle kalitenin yüksek olduğu yerlerde yetiştirilmesi gerekmektedir. Belirtilen şekilde iyi bir planlamayla, hem ürün ve kalite kayıları azaltılabilir hem de o ürün bazında markalaşma sağlanabilir. Bu çalışmada, markalaşmanın önemi, bahçe ürünlerinde markalaşmanın önündeki engeller ve çözüm önerilerinin sunulması amaçlanmıştır.

\section{Türkiye'nin Bahçe Bitkileri Tarımındaki Yeri}

Türkiye İstatistik Kurumu (TÜİK) 2016 yılı verilerine göre, Türkiye tarımında bitkisel üretim yaklaşık 24 milyon hektarlık bir alanda yapılmakta, bu alanın 4 milyon hektarı bahçe bitkileri tarımı için kullanılmaktadır (Anonim, 2018c).

Bahçe bitkilerinin, toplam bitkisel üretim alanları içindeki payı \% 17, Türkiye toprakları içindeki payı ise $\% 5$ dolaylarındadır. Genel olarak ülke toprağının \% 2'sini bahçe bitkilerine ayıran ülkeler bahçe bitkileri ülkesi olarak kabul edildiğinden, Türkiye rahatlıkla bir bahçe bitkileri ülkesi olarak adlandırılabilir (Ağaoğlu ve ark., 2010).

Türkiye' de bahçe bitkileri yetiştiriciliği şehirlerin tanınmasında da etkili olmuştur. $\mathrm{Bu}$ etkiyle birlikte birçok yerleşim merkezi belirli bahçe bitkisiyle birlikte anılır hale gelmiştir. Örneğin, Giresun, fındık; Rize, çay; Aydın, incir; Amasya, Amasya elması; Malatya, kayısı; Gaziantep, antepfistığı; Isparta, gül; Bursa, şeftali; Niğde, patates; Kastamonu (Taşköprü), sarımsak ve Bursa, kestane ile anılır hale gelmiştir.

Tarım ve tarım içinde bahçe bitkileri Türkiye ekonomisinde önemli bir paya sahiptir. Türkiye diş ticaret gelirleri içinde en büyük pay ( $\%$ 93.4) sanayiye ait olup, bunu tarım ürünleri $(\% 4.0)$ ve maden ürünleri (\% 1.94) izlemektedir. Tarım ürünleri içinde bahçe ürünlerinin payı ise \% 53 dolayındadır. Bu veriler, bahçe bitkilerinin Türkiye dış ticaretinde önemli bir yeri olduğunu da göstermektedir (Anonim, 2018c).

Bahçe bitkileri alanında önemli bir üretici olan Türkiye'de, arazi kullanımında bazı sorunları bulunmaktadır. Türkiye'de, arazi kullanımındaki hatalar ve miras yoluyla bölünmelerin sonucunda, işletmelerde hem arazi varlığı azalmakta, hem de aşırı parçalı bir araziye sahip olma oranı 
artmaktadır. Bu durum; yaklaşık yıllık 17 milyar TL'lik üretim kayıpları, rekabet edebilir bir üretim yapılamaması ve üretim maliyetlerini artmas1, ekonomik anlamda üretim yapilabilecek arazinin azalması, sulama ve arazi toplulaştırması gibi altyapı yatırımlarının çok daha pahalıya mal olması ve yatırımların etkinliğinin azalması gibi bir dizi ekonomik kayıpları da beraberinde getirecektir.

Yukarıda sıralanan sorunların çözümü için 5403 sayılı Toprak Koruma ve Arazi Kullanımı Kanununda Değişiklik Yapılması Hakkındaki Kanun 15 Mayıs 2014 Tarihli Resmi Gazete'de yayımlanarak yürürlüğü girmiştir (Anonim, 2018a).

\section{Marka ve Markalaşma}

Marka ve markalaşma günümüzün önemli konu ve kavramlarındandır. Marka kavramı, "Bir satıcının veya saticilar grubunun, mal ve hizmetlerini tanımlayan ve onları rakiplerinden ayırt etmeyi amaçlayan bir isim, terim, işaret, sembol, şekil ya da bunların birleşimi" olarak tanımlanmaktadır (Çeliktel, 2008; Anonim, 2017a; Anonim, 2017b).

Bir malın, marka bir mal olarak kabul edilebilmesi için pazarda bulunan diğer mallardan bazı farklı özellikleriyle ayrılması gerekmektedir. Bunlar (Çeliktel, 2008) aşağıda verilmiştir;

- Mal1, benzerlerinden ayıran bir işareti veya bir sembolü bulunmalıdır. Mal, ortalamanın üzerinde bir kalite düzeyine sahip olmadır.

- Malın, tüketici gözünde bir imajı olmalı ve pazarda tanınmalı, diğer bir deyişle pazarda özel bir konumu bulunmalıdır.

- Mal, her yerde bulunabilmelidir.

Markalaşma sürecinin başarıya ulaşmasında, bilinçli tutumlar yanında yeterli bir sermayenin olması da gerekmektedir (Çeliktel, 2008).

Markalaşma; üreticiye, sanayiciye ve tüketiciye birçok yararlar sağlamaktadır. Bu yararlar; akılda kalıcılık, bağlılık, bilinirlik, seçkin imaj, seçkin fiyat, büyüme, daha büyük şirket öz kaynağı, daha düşük pazarlama harcamaları ve tüketiciler için daha az risk olarak siralanabilir (Anonim, 2017c).

Günümüz pazarlarında yaşanan hızlı gelişmeler pazarda rekabet edebilmeyi güçleştirmektedir. İşletmelerin, benzer ürünlerde rekabet üstünlüğü sağlamak için fiziksel farklılıklar yerine marka gibi soyut faydalara yöneldiği görülmektedir. Marka, hem tüketicinin ürün ve hizmete ilişkin düşüncesini yansitmakta hem de firmalar arasındaki rekabette önemli bir rol oynamaktadır. Çünkü marka, ürünü tanımlayıcı parçalardan biri olup ürüne değer katmaktadır. Güçlü markalar, uzun ve kısa vadede satışların ve gelirlerin artmasını sağlayabildiğinden, güçlü markalar oluşturarak pazarda uzun süre kalabilmek hedeflenmektedir (Alan ve Yeloğlu, 2013).

Marka oluşturma kadar markanın devamlılığı da önem taşımaktadır. İhtiyaçtan fazlasının satın alınmadığı bir sektör olan tarım ve gıda sektöründe bu konu daha büyük önem taşımaktadır. Marka oluşturabilmek ve markanın devamlılığını sağlayabilmek için çeşitli çalışmaların yapılması gerekmektedir. $\mathrm{Bu}$ amaçla; yetiştiricilik/üretim öncesinde pazar araştırmasının yapılması, pazardaki boşlukların belirlenmesi, hedef kitlenin belirlenmesi, hedef kitlenin tüketim alışkanlıklarının belirlenmesi, hedef kitle ile ürün ve marka arasında bir ilişkinin kurulması ve tüketicilerin ürün hakkındaki algısının dikkate alınması gerekmektedir.

Markalaşma, aynı zamanda kaliteyi pazarlama stratejisi olarak da yorumlanmaktadır. Üretimde kalite önemli olmakla birlikte, kalitenin tüketiciye ulaştırılabilmesi pazarlama sistemleriyle mümkün olabilmektedir. Hatta bahçe ürünlerinde pazarlama, üretim öncesinden tüketiciye ürünlerin ulaşmasına kadar olan bir süreç olarak değerlendirilmektedir.

Markalaşma için, öncelikle ürünün satılmasında hedeflenen piyasa ya da kitlenin belirlenmesi gerekmektedir. Ürünlerin veya hizmetlerin markalaşabilmesi, onların iç ya da diş piyasalarda (nasıl ve ne şekilde) pazarlanabilmesine bağlı olarak oluşmaktadır. Markanın pazarda kalabilmesi ise devamlılığına bağlı olarak gerçekleşmektedir.

\section{Türkiye'nin Bahçe Bitkilerinde Markalaşma Durumu ve Potansiyeli}

Türkiye, sahip olduğu biyolojik ve ekolojik zenginlikleriyle birlikte tarımsal üretimde standart kaliteyi her zaman yakalayabilecek potansiyele sahiptir. Türkiye'de yaklaşık 10000 (bazı araştırıcılara göre 9000-9500 adet) adet bitki türü doğal olarak yetişmekte olup, bunun 3000'den fazlasını (3072 adedini) endemik bitkiler oluşturmaktadır. Türkiye'de endemizm oranı \% 3035 dolayındadır. Tüm Avrupa kıtasındaki bitki sayısının 12000 dolayında olduğu düşünüldüğünde, Türkiye'nin biyolojik zenginliği çok daha iyi görülebilmektedir (Yücel ve Babuş, 2005; Günal, 2013). Türkiye sahip olduğu bu potansiyelin bir kısmını kullanmasına karşın, önemli bir kısmı halen atıl durumda bulunmaktadır.

Türkiye tarımında markalaşmalar olmakla birlikte, markalaşmada çeşitler yerine il-ilçe ve tür etkileşiminin öne çıktığı görülmektedir Buna örnek olarak Malatya kaysısı, Kütahya vişnesi, Tokat domatesi gibi adlandırmalar verilebilir. Diğer 
yandan, uluslararası ticarette de Türk findığı, Türk kirazı, Türk limonu gibi adlandırmalarla ülke adıyla markaların oluştuğu da görülmektedir.

Ticari bir marka olarak oluşmasa bile, tüketici memnuniyetiyle birlikte markalaşmaların olduğu görülmektedir. Üretimlerin planlı, bilinçli ve hedef pazar istekleri dikkate alınarak yapılması, markalaşma yanında marka değerinin korunmasını da sağlayacaktır. Doğu Karadeniz Bölgesi'nde çay, kalitesi ve devamlılığıyla birlikte bir marka üründür. Aynı şekilde Giresun ve Ordu illerinde findık, Tokat ilinde sırık domates, Aydın ilinde incir, Kastamonu ili Taşköprü ilçesinde sarımsak doğal olarak oluşmuş bir markadır. Sıralanan bu örneklerde ve diğer ürünlerde marka değerinin korunması ve arttırılmasına yönelik çalışmalar yapılmakla birlikte, bu çalışmalar yeterli düzeyde olmadığından, çalışmaların artarak devam etmesi gerekmektedir.

Günümüzde birçok üretim bölgesinde belirli ürünler için coğrafi işaret alma çalışmaları ön planda tutulmaktadır. Coğrafi işaret, "belirgin bir niteliği, ünü veya diğer özellikleri itibariyle kökenin bulunduğu bir yöre, alan, bölge veya ülke ile özdeşleşmiş bir ürünü gösteren ad veya işaretlere" verilmektedir. Coğrafi işaretler, ayırt edici özelliği ile ön plana çıkan ve bulunduğu bölge ile özdeşleşen doğal ürünler, tarım, maden ve el sanatları ile sanayi ürünlerine verilmektedir. Coğrafi işaretlemenin amacı, coğrafi işarete konu olan ürünün kalitesinin korunması, bilinen özellikte üretiminin sağlanması, coğrafi işarete konu olan yörede veya özellikte üretim yapanların korumadan öncelikli olarak yararlanmalarının sağlanması yanında, ülkenin milli ve kültürel değerlerinin korunmasıdır. Coğrafi işaretlerin tescilinin amacı ise, genel nitelikleri itibariyle üretimi, kaynağ 1 gibi bir takım yerel niteliklerine bağlı olarak belli bir üne kavuşmuş ürünlerin korunmasını sağlamaktır (Anonim, 2017d; Anonim, 2017e).

Coğrafi işaretler, "menşe adı" ve "mahreç işareti" olarak ikiye ayrılmaktadır. Coğrafi işaret konulmasına konu edilen ürünün üretimi, işlenmesi ve diğer işlemlerinin tamamı, sınırları belirlenmiş coğrafi alanda gerçekleşmek zorunda ise bu durumda bulunan coğrafi işaretlere menşe adı denilmektedir. Menşe adı, menşe adına konu ürünün tamamı ile tanımlanan yerde üretilmiş olmasını gerektirmektedir. Buna örnek Malatya kayısısı verilebilir. Mahreç işaret ise, ürünün üretimi, işlenmesi ve diğer işlemlerinden en az biri, sınırları belirlenmiş coğrafi alanda gerçekleşmek zorunda ise bu durumda verilen coğrafi işarettir (Anonim, 2017d; Anonim, 2017e). Buna örnek olarak da Çorum leblebisi verilebilir. Tarımsal üretimde yetiştiricilikte menşe adı üzerinden, işlenmiş gıda ürünlerinde ise mahreç adı üzerinden coğrafi işaret alma çalışmaları yapılmaktadır.

Türkiye'nin yaklaşı 48 milyon tonluk bahçe bitkileri üretimiyle (Anonim, 2018b) birlikte yüksek kaliteli tarım ürünleri üretmesine karşın üretilen ürünlerde yeterince markalaştığını söylemek mümkün değildir.

Türkiye tarımında ve bahçe bitkileri sektöründe markalaşmayı kısıtlayan çeşitli faktörler bulunmaktadır. Bu faktörler aşağıda sıralanmıştır;

- Her yerde her ürünün yetiştirilmeye çalışılması,

- Tarım işletmelerinin çoğunun arazi varlıklarının küçük olması,

- Aile işletmelerinin fazla olması,

- Tarım işletmelerinin birlikte hareket etme yerine bireysel davranmaları,

- Pazarlamada kalite etkisinin yeterince kavranılmamas1,

- Standardizasyon uygulamalarının iç pazarda önemli bir konu olarak algılanmamas1,

- Bir tür bazında üretimleri düşük çok fazla çeşit yetiştirilmesi,

- Ürünler için gerekli materyali sağlayan firma ve materyal çeşitliliğinin yetersiz olması,

- Üretimin bir planlamayla değil işletmelerin bireysel tercihlerine göre yapılması,

- Farklı değerlendirme şekillerine uygunluğun yetersiz olmas1,

- Aile işgücünün giderek azalması,

- İç pazara sunulan ürün talebinde (tüketici tercihinde) marka baskısının yeterince olmaması,

- Halen oluşan markaların ürün üzerine değil ürünü toplayıp işleyen ve pazarlayan firmalar düzeyinde olmas1,

- İç piyasaya markalı ürün sunan firmaların genellikle ihracatçı firmalarla sınırlı kalması.

Yukarıda sıralanan markalaşmanın önündeki engellere rağmen, Türkiye'nin bahçe bitkilerinde (genel olarak da tarım ürünlerinde) markalaşmayı kolaylaştıracak yönleri de bulunmaktadır. Bunlar aşağıda sıralanmıştır;

- Türkiye'nin bir tarım ve bahçe bitkileri ülkesi olmas1,

- Ekolojik zenginlik,

- Coğrafik konum ve pazarlara yakınlık, 
- Ulaşım ve iletişimdeki gelişmelerle uzak pazarlara ürün gönderebilme,

- Biyolojik zenginlik ve çeşitlilik,

- Tarımsal alanda çalışmalar yapan lisans ve lisansüstü ünvanlara sahip Ziraat Mühendislerinin artmas1,

- Tarımsal alanda çalışmalar yapan üniversite, fakülte, yüksekokul, araştırma enstitüleri ve özel sektörün artmas1,

- Bilimsel faaliyetler sonucunda yeni genotiplerin geliştirilmesi,

- Sınai Mülkiyet Kanununun çıkması,

- Tarım alanlarının miras yoluyla çok küçük alanlara bölünmesini engelleyecek kanunun çıkması (5403 sayılı Toprak Koruma ve Arazi Kullanımı Kanununda Değişiklik Yapılması Hakkındaki Kanun),

- Milli Tarım Projesi Havza Bazlı Destekleme Modeli kapsamında, Türkiye'de arz açığı bulunan, stratejik öneme haiz ve bölgesel önem arz eden ürünlere en uygun yetiştirme alanları (havzalar) dikkate alınarak desteklemelerin yapılması,

- Tarım ürünlerinin gıda ve gıda dışındaki birçok sanayi kolu için hammadde olarak sunulabilmesi,

- Tarım ürünlerinin sağlıklı yaşam (çeşitli hastalıkların tedavisi) için sürekli gündemde tutulmas1,

- Türk halkının tarımsal üretim kültürüne sahip olmas1,

- Türk halkının tarımsal üretimi sevmesi,

- Türkiye'de tarımsal ürün tüketiminde çeşitliliğin olması,

- Popülerlik kazanan tarım ürünlerinin kısa zamanda üretilerek tüketime sunulabilmesi,

- Türk halkında insanların özellikle gıda gibi zorunlu ihtiyaçlarını giderme ve onlara yardımcı olma duygularının üst düzeyde olmasıyla birlikte, tarımsal üretimi bu yönden de değerlendirmesi,

- Büyük işletmelerden küçük aile işletmelerine kadar farklı büyüklükte ve kültürde işletmelerin üretim faaliyetlerinde bulunması,

- Bölge, il veya ilçe bazında bazı ürünler için markalaşmanın bulunması.

\section{Bahçe Ürünlerinde Kalite ve Kalite Üzerine Etki Yapan Faktörler}

Kalite, bir üründe tüketicinin beklentilerinin karşılanabilme durumunu ifade eden bir kavramdır.
Bahçe ürünlerinde kalite, iç ve diş kalite olarak ikiye ayrılmaktadır. İç kalite, tüketicinin ürünü tüketim aşamasındaki (tat, lezzet, sululuk, aroma vb) algılarından oluşurken; dış kalite, ürünün (şekil, irilik, renk, görünüş bozuklukları vb) görünümünden oluşmaktadır (Karaçalı, 2009).

Ürününün satışında öne çıkan hatta belirleyici olan kalite, diş kalitedir. Bu nedenle, yetiştirilecek veya 1slah yoluyla geliştirilecek çeşitlerde diş kalitenin yüksek olması büyük önem taşımaktadır.

Kalite, öncelikle genetik yapıyla kontrol edilen diğer bir ifadeyle çeşitlerin genetik yapısı tarafindan belirlenen bir özelliktir. Kalite üzerine ikinci derecede ekoloji ve son olarak da kültürel uygulamalar etkili olmaktadır. Bazı çeșitlerin ekoloji seçicilik özelliği bulunduğundan bu çeşitlerin yüksek kalite için öncelikle en iyi kaliteyi verebileceği ekolojik alanlarda yetiştirilmesi gerekmektedir.

Markalaşma için standardizasyonun sağlanması gerekmektedir. Standardizasyon için de çeşitler bazında yeterli üretimlerin yanında, standart kalite sınıflarına giren yeterli düzeyde ürünün olması da gerekmektedir. Kalite, markalaşma için şart olmakla birlikte tek başına yeterli değildir. Markalaşma için, ürün miktarındaki yeterlilik ve pazarda bulunma süresi gibi faktörlerin de istenilen düzeyde olması gerekmektedir.

Bahçe ürünlerinde ve genel olarak da tarım ürünlerinde standardizasyon aşağıda verildiği gibi 3 aşamada sağlanabilir (Özcan, 1995).

1. Genetik yapıda standardizasyon: Bir bölgede çok sayıda tür ve çeşit yetiştirmek yerine sınırlı sayıda ve kitlesel üretim yapabilecek düzeyde kaliteli çeşitlerin yetiştirilmesi gerekir. $\mathrm{Bu}$ yapıldığında çeşit bazında yeterli üretimler sağlanmış olabilecektir.

2. Kalitede standardizasyon: Ürünlerin standartlarda bildirilen kalite sinıflarına ayrılmasıyla sağlanabilir.

3. Ambalajda standardizasyon: Kalite sınıflarına ayrılan ürünlerin standart ambalajlara her sınıfı temsil edecek şekilde ayrı ayrı yerleştirilmesiyle sağlanabilir.

Yukarıdaki bilgiler, bir bölgede her türü ve çeşidi yetiştirmek yerine, o bölgede en iyi olabilecek sınırlı sayıda tür ve çeşitlerle (kitlesel üretim yapabilecek düzeyde) üretimlerin yapılmasının gerekliliğini ortaya koymaktadır.

\section{Sonuç ve Öneriler}

Bahçe ürünleri, artan dünya nüfusu için en önemli besin kaynaklarını oluşturmaktadır. Bir tarafta 
yetersiz ve dengesiz beslenmeden dolayı sağlıksız yaşam sürmek zorunda olan insanlar bulunurken, diğer tarafta üretilen ürünlerin bir kısmı tüketiciye ulaştırılamadan çürütülüp çöpe atılmaktadır.

Günümüzde iletişim ve ulaşım alanındaki gelişmeler ürün ve kalite kayıplarını azaltmada yeterli olamamıştır. İletişim ve ulaşımdaki gelişmeleri fursata çevirebilmek için üretimin arz/talep dengesine göre yapılması, kaliteli üretimlerin yapılması, hasat öncesi ve hasat sonras1 uygulamaların doğru ve yeterli düzeyde yapılması yanında iyi bir pazarlama ağının da kurulması gerekmektedir.

Pazarlamayı kolaylaştıracak önemli bir aşamada markalaşmadır. İşlenmiş tarım ürünlerinde markalaşma zorunlu olarak ortaya çıkmakla birlikte, yaş meyve-sebzeler gibi işlenmemiş tarım ürünlerinde böyle bir zorunluluk bulunmamaktadır. Ancak, kalite ve kalitedeki devamlılığa bağlı olarak il bazında, ilçe bazında veya o ürünleri pazarlayan firmalar bazında markalaşmaların oluştuğu görülmektedir.

Marka tüketici için güven veren bir unsurdur. $\mathrm{Bu}$ nedenle marka olma ve markalaşmalar tüketici tercihlerinde büyük kolaylık sağlayacağı gibi, üreticiler için de talep düzeyini daha net olarak ortaya çıkaracaktır.

Tarım sektöründe markalaşmanın giderek arttığ1 görülmekle birlikte. markalaşmanın sadece reklamla yapılabileceği düşüncesinin arttığ1 görülmektedir. Yapılan reklamlarda tüketiciye yeterince güven verilememektedir. Sosyal ağları ve interneti kullanma oranının arttığı günümüzde reklamlarda güvenilirliğin azalma önemli bir sorun oluşturmaktadır. Bu durum özellikle tarımsal ürün satışında çok daha belirgin olarak görülmektedir. Standartlara uygun üretim ve sunum yapılmadığında ürünün ve üreticinin marka değeri düşmektedir.

Türkiye'de tarım işletmelerinin çoğu arazi varlıklar nedeniyle küçük işletmeler konumundadır. $\mathrm{Bu}$ küçük işletmelerin ürettikleri ürünler bazında (üretimlerin azlığı nedeniyle) markalașabilmesi mümkün olamamaktadır. Bunların, örgütlü olarak (üretici birlikleri, kooperatifler veya bir şirket adı altında toplanarak) üretim ve pazarlama organizasyonlarını yapmaları durumunda markalaşmaları mümkün olabilecektir.

Tarım ürünlerinde pazarlama faaliyetlerinin üretime başlamadan önce değerlendirilmesi gerekmektedir. Üretim sonrası pazar arayışları önemli ölçüde ürün ve kalite kayıplarına neden olmakta, aynı zamanda (arz/talep dengesine göre) oluşan fiyatlar nedeniyle tarımsal faaliyetin ekonomik karşılı̆̆ı da alınamamaktadır.
Tarım ürünleri ve bu ürünler içinde hasat sonrası ömürleri kısa olan bahçe ürünlerinde markalaşma, hem pazarlamayı kolaylaştıracak hem de tüketiciye kaliteli ürün sunulması sağlayacak önemli bir uygulama olarak görülmelidir. Tarımsal faaliyet içinde olanların, üretim ve pazarlama aşamalarında toplumsal değerlere sahip çıkmaları ve çevreye dost olmaları gerekmektedir.

\section{Kaynaklar}

Ağaoğlu, S., Çelik, H., Çelik, M., Fidan, Y., Gülşen, Y., Günay, A., Halloran, N., Köksal, İ., Yanmaz, R., 2010. Genel Bahçe Bitkileri. Ankara Üniversitesi Ziraat Fakültesi Yayınları. No: 1579, Ankara.

Alan, H., Yeloğlu, O., 2013. Markalaşma ve yenilikçilik. Siirt Üniversitesi İktisadi ve İdari Bilimler Fakültesi İktisadi Yenilik Dergisi, 1(1): 13-26.

Anonim, 2017a. 22.12.2016 Tarihli ve 6769 Numaralı Sinai Mülkiyet Kanunu, Marka Hakkı ve kapsamı. (http://www.mevzuat.gov.tr/MevzuatMetin/1.5.6769 .pdf), (Erişim tarihi: 29.06.2017).

Anonim, 2017b. Marka nedir? (https://www.turkticaret. net/marka-nedir), (Erişim tarihi: 29.06.2017).

Anonim, 2017c. Markalaşma nedir? İstanbul İşletme Enstitüsü, (http://www.iienstitu. com/ markalasmanedir/), (Erişim tarihi: 29.06.2017).

Anonim, 2017d. Coğrafi işaret nedir? (http://www.tesk. org.tr/tr/calisma/sinai/cografi.html), (Erişim tarihi: 25.06.2017).

Anonim, 2017e. Coğrafi işaretler ve geleneksel ürün adları. (http://www.turkpatent.gov.tr/), (Erişim tarihi: 25.06.2017).

Anonim, 2018a. Gerçek alan ve izdüşüm alan. (https://cografyabilim.wordpress.com.), (Erişim tarihi: 25.06.2018).

Anonim, 2018b. Tarımsal örgütlenme tablosu (Ocak 2018). (https://www.tarim.gov.tr/TRGM/Link/33/TarimsalOrgutlenme-Tablosu.), (Erişim tarihi: 29.06.2018)

Anonim, 2018c. Bitkisel Üretim Kayıtlar1. (www.tuik.gov.tr), (Erişim tarihi: 29.06.2018).

Çeliktel, S., 2008. Markalaşma süreci ve stratejilerinin incelenmesi. Uzmanlık Tezi, T.C. Türk Patent Enstitüsü Markalar Dairesi Başkanlığı, Ankara, s. 59.

Günal, N., 2013. Türkiye'de iklimin doğal bitki örtüsü üzerindeki etkileri. Acta Turcica Çevrimiçi Tematik Türkoloji Dergisi, 5(1): 1-22.

Karaçal1, İ., 2009. Bahçe Ürünlerinin Muhafaza ve Pazarlanması. Ege Üniversitesi Ziraat Fakültesi Yayınları. No: 494, İzmir.

Kızılaslan, H., Doğan, H.G., 2013. AB ve Türkiye'de tarım sektöründe örgütlenme ve üretici birlikleri. Sosyal Bilimler Araştırmaları Dergisi, 1: 146-159.

Özcan, M., 1995. Tarım ürünlerinde standard ve kalitenin yeri ve önemi. Standard, 34(407) : 89-92.

Yücel, M., Babuş, D., 2005. Doğa korumanın tarihçesi ve Türkiye'deki gelişmeler. Doğu Akdeniz Ormancılık Araştırma Müdürlüğü Dergisi, 11: 151-175. 